\title{
O QUÍMICO E NATURALISTA LUSO-BRASILEIRO ALEXANDRE ANTONIO VANDELLI
}

\author{
Adílio Jorge Marques" e Carlos A. L. Filgueiras* \\ Instituto de Química, Universidade Federal do Rio de Janeiro, CP 68563, 21945-970 Rio de Janeiro - RJ, Brasil
}

Recebido em 10/12/08; aceito em 18/5/09; publicado na web em 20/10/09

\begin{abstract}
THE LUSO-BRAZILIAN CHEMIST AND NATURALIST ALEXANDRE ANTONIO VANDELLI. Alexandre Vandelli was the heir of two illustrious scientific traditions in the Luso-Brazilian world of the late eighteenth and early nineteenth centuries, that of his father, the celebrated Italian-Portuguese naturalist and chemist Domingos (Domenico) Vandelli, and that of his father-in-law, that protean figure in several scientific specialties as well as in politics, José Bonifácio de Andrada e Silva, who in later life was of paramount importance in the process of Brazilian independence from Portugal. The younger Vandelli followed their footsteps but soon engaged in a multiple career, at first in Portugal and later in Brazil, of which little is known and is here presented for the first time.
\end{abstract}

Keywords: Alexandre Vandelli; Luso-Brazilian science; XIX ${ }^{\text {th }}$ century Brazilian science.

Este artigo apresenta a vida e a obra do quase desconhecido químico e naturalista oitocentista Alexandre Antonio Vandelli (17841862), português naturalizado brasileiro que atuou nas mais diversas áreas do saber em Portugal e no Brasil.

Tendo produzido um leque de trabalhos importantes em diferentes campos do conhecimento, sua obra pode parecer menor comparada àquela da dinastia científica de que provém. Contudo, de um ponto de vista histórico ela possui enorme importância ao pôr em evidência as dificuldades e contradições presentes tanto em seu país de origem (Portugal) como no Brasil adotivo, num período em que ambos os países se esforçavam para inserir a ciência moderna em sua cultura. $\mathrm{O}$ esquecimento a que Alexandre Vandelli foi relegado também se deve ao fato de ele ter sido o herdeiro e continuador de duas figuras de enorme importância na história luso-brasileira.

Por um lado, Alexandre era filho de Domingos (Domenico) Vandelli (1735-1816), naturalista e químico trazido de Pádua por Pombal e que teve atuação tão destacada tanto em sua cátedra na Universidade de Coimbra quanto na importante Academia Real das Ciências de Lisboa, além de várias outras atividades. Domingos chegou a Portugal em 1764, passando à Universidade de Coimbra em 1772. ${ }^{1}$ Por outro lado, Alexandre Vandelli viria em 1819 tornar-se genro do mais célebre discípulo de Domingos Vandelli, José Bonifácio de Andrada e Silva (1763-1838). Bonifácio foi renomado cientista não só em Portugal como também em vários países da Europa, tornandose mais tarde figura de proa no processo de independência do Brasil da sua metrópole. ${ }^{2}$

A frondosa sombra de antecessores tão ilustres parece ter contribuído para obliterar o interesse pelo segundo Vandelli. Todavia, uma apreciação de sua vida e obra poderá contribuir para um melhor entendimento do pensamento científico em Portugal e no Brasil em seu período produtivo de vida.

Alexandre Vandelli nasceu imerso nas idéias iluministas do pai e atravessou momentos marcantes e difíceis da história de Portugal e do Brasil. Após décadas de vida em Portugal, toda a família Vandelli enfrentou problemas políticos de enorme monta e imensas dificuldades financeiras disso decorrentes, principalmente a partir da segunda década do século XIX.

"Programa de Pós-Graduação em História das Ciências e das Técnicas e Epistemologia, CentrodeTecnologia,Bl.A,UniversidadeFederal do Riode Janeiro *e-mail: calf@iq.ufrj.br
O grande afluxo de estudantes brasileiros à Universidade de Coimbra diminuiu drasticamente a partir do início do século XIX. Este número havia alcançado cifras bem expressivas no século anterior, quando 759 brasileiros lá se matricularam de 1701 a 1750, seguidos por 994 estudantes da mesma origem no período 1751-1800. A diminuição mencionada se deveu, sobretudo, pela instalação de cursos superiores no Brasil, mas também pelo maior intercâmbio entre o Brasil e outros países, em detrimento de Portugal. ${ }^{3}$

Alexandre Vandelli tornou-se, a partir de 1813, assistente de José Bonifácio de Andrada e Silva, tanto no Laboratório Químico da Casa da Moeda de Lisboa quanto na Intendência Real das Minas e Metais do Reino. Alexandre se casou em 18 de fevereiro de 1819 (Lisboa) com Carlota Emília de Andrada, nascida a 20 de dezembro de 1790 e filha primogênita de José Bonifácio, reforçando assim os antigos laços dos Andrada com a família Vandelli. ${ }^{4}$ Carlota era uma das duas filhas legítimas de Bonifácio com Narcisa Emília O'Leary, com quem seu pai se casara em 1790. Uma terceira filha de José Bonifácio, oriunda de outro relacionamento (ainda incógnito aos historiadores) seguiu com os Andrada para o Brasil em 1819. Ambos, Alexandre Vandelli e Bonifácio, além de trabalharem juntos, moravam na mesma Rua de São Bento em Lisboa. ${ }^{5}$

O casamento da filha foi um dos últimos preparativos para que José Bonifácio pudesse, enfim, realizar seu antigo sonho: livrar-se das atividades burocráticas em Portugal e retornar à terra natal. Bonifácio vivia muito provavelmente terríveis conflitos à época, como se verifica em trecho de carta a um amigo ignorado, datada de 30 de março de 1818:

“...como o bom Job, não tenho amaldiçoado a hora em q. fui concebido, e ainda mais a hora em q. fui pai! Porém ao mesmo tempo devo confesar, q. esta família, q. me hé tão cara, he q. ${ }^{m}$ me tem impedido de não ter já tomado algu'a resolução heróica.

...e os meos livros e pedras são hoje a $m^{a}{ }^{a}$ única consolação - nunca estudei tanto na minha vida; e talvez ainda poderia ser feliz, se me dessem a $\mathrm{m}^{\circ}{ }^{\circ}$ carta de alforria. Mas para disgraça minha o requerim. ${ }^{\text {to }} q$. levou, e em que confiava vejo que terá a mesma sorte, q. os outros dois anteced. ${ }^{\text {tes." }}$.

Mais adiante escreve ainda: “Já não posso com o peso, q. carrego 
sobre meos hombros; e so suspiro por entranhar-me nos matos de S. Paulo; onde ao menos tenha bananas carne de porco e farinha de páo à fartura". ${ }^{6}$

Alexandre Vandelli e Carlota Emília tiveram quatro filhos, dos quais os três mais velhos nasceram em Lisboa e a última em Santos, no Brasil. A primogênita foi Narcisa Emília de Andrada Vandelli, futura Viscondessa de Sepetiba por casamento com o Visconde, Aureliano de Souza Oliveira Coutinho, Ministro, Senador e Conselheiro do Imperador D. Pedro II. Nasceu em 1820 e viria a ser Dama Honorária da Imperatriz Teresa Cristina. Em seguida, José Bonifácio de Andrada Vandelli (1821), que se tornou militar, radicando-se posteriormente em Minas Gerais e finalmente no Paraná. Feito Cavaleiro da Ordem de S. Bento de Aviz em 1861. ${ }^{7}$ A seguir, Feliciana Emília de Andrada Vandelli (1822). Feliciana foi casada com o Conselheiro do Império Joaquim Maria Nascentes de Azambuja. A caçula, Júlia de Andrada Vandelli, viria à luz em 1836 na cidade de Santos e não deixaria geração conhecida. ${ }^{8}$

Em 1834 caía D. Miguel, vencido nas armas por seu irmão mais velho D. Pedro IV, o ex-Imperador brasileiro D. Pedro I, que lutou pelos direitos dinásticos de sua filha Maria da Glória, a futura Maria II de Portugal. Alexandre Vandelli, partidário de D. Miguel, decidiu então emigrar com a família para o Brasil em dezembro de 1833. Após algum tempo morando em Santos, veio para a capital do Império. Tornou-se mestre da família imperial, e viveu no Rio de Janeiro por mais 28 anos até o término de seus dias em 1862.

No Brasil Alexandre Vandelli vivenciou muitas questões políticas, como a maioridade de D. Pedro II, o liberalismo e a forte influência inglesa na vida política e econômica do segundo Império. O país ainda estava em fase de construção de sua identidade política e cultural, e encontrou em mentes ilustradas, como as do círculo dos Andrada (inclua-se Alexandre Vandelli) um vetor para a implementação do pensamento científico na elite intelectual e social. E o maior representante era o próprio Imperador D. Pedro II.

Dividiremos este trabalho, para fins de melhor apresentação, em duas fases a vida e obra de Alexandre Vandelli. Inicialmente a fase portuguesa, período de seu nascimento até 1833, quando vem para o Brasil. Aqui nos ocuparemos em mostrar os fatos importantes relacionados à sua vida e atuação nas atividades científicas da época. Em seguida, trataremos do período de 1834 até sua morte no Rio de Janeiro em 1862, à qual denominaremos de fase brasileira, marcada também por uma pluralidade de atividades ligadas às ciências.

É importante ressaltar que a data de sua morte tem sido divulgada até aqui de maneira incorreta, tanto em Portugal quanto no Brasil. Alexandre Vandelli faleceu em 13 de agosto de 1862, tendo sido sepultado no dia seguinte na cidade do Rio de Janeiro, como os principais jornais da época noticiaram. ${ }^{9}$

\section{A FASE PORTUGUESA}

Alexandre Antonio Vandelli nasceu em Coimbra a 27 de junho de 1784, quando seu pai, Domingos Vandelli, ocupava o cargo de Professor Catedrático de Química e História Natural da Universidade de Coimbra. Domingos permaneceu nessas funções de 1772 a 1791, quando se jubilou. ${ }^{10}$ Alexandre era o filho mais velho de uma família que naquela altura já havia adquirido prestígio em Portugal.

Desenvolvendo-se nas leituras com seu pai, expoente português da ciência lusa iluminista, Alexandre Vandelli aparecerá sempre ligado às ciências naturais.

É preciso fazer aqui outra ressalva histórica. Sua cidade natal não é Lisboa, como muitas vezes também se informa em várias fontes, ${ }^{11}$ e sim Coimbra, segundo declaração do próprio Alexandre Vandelli inscrita no livro de "Constituição, Juramento e Admissão de Estrangeiros do Império (1833-1859)". ${ }^{12}$ Este livro consta de seu processo de naturalização no Brasil em 1838, como foi por nós verificado.

Sua mãe, Feliciana Isabella Bon, era de origem francesa e foi acusada em 1810 de estar ligada ao francês Geoffroy de Saint-Hilaire, naturalista que esteve em Portugal quando das invasões napoleônicas. Saint-Hilaire foi para Portugal para recolher amostras dos museus lusos, com o intuito de levar à França tudo o que pudesse ser de interesse ao naturalismo. ${ }^{13}$ Tal fato será usado contra a família Vandelli durante a Setembrizada, movimento político ocorrido a partir de 10 de Setembro de 1810, quando várias pessoas foram perseguidas em Portugal por suspeita de afrancesamento (ou seja, de simpatizar e colaborar com os invasores franceses). A acusação foi aplicada também ao velho Professor Domingos Vandelli, na época já com 75 anos, e que foi preso e conduzido para o Forte de São Julião da Barra em Lisboa junto com o filho Alexandre Vandelli. Embarcados com destino à Ilha Terceira nos Açores, no dia 25 de setembro chegaram a Angra e no dia 26 desembarcaram. Outros motivos da perseguição contra Domingos Vandelli foram sua ligação com a maçonaria portuguesa, além de alugar um quarto de suas dependências em Lisboa para um inquilino considerado jacobino. ${ }^{14}$

Em virtude de sua desventura, a família Vandelli passou na década de 10 do século XIX por sérios problemas financeiros. Alexandre Vandelli logo conseguiu regressar do exílio a Lisboa, porém o pai só retornará após deixar os Açores em 1811 e viver em Londres até 1815. Alexandre Vandelli tornou-se procurador do pai durante todo esse intervalo de tempo, sendo requerente junto ao Regente de perdão para a pena imposta ao seu pai. ${ }^{15}$

É importante citar que entre os vários argumentos que Alexandre Vandelli utiliza para defender a memória de seu pai, o primeiro se refere a:
"Que elle veio a Portugal crear as duas cadeiras de Chimica (grifo nosso), e Historia Natural, que de novo se estabele- cerão, pela Gloriosa reformação dos Estudos, assim como o Real Jardim Botânico d'Ajuda, e o da Universidade de Coimbra, sendo, por isso, o primeiro, que deu à Nação Por- tugueza estes importantes conhecimentos, tam úteis às Artes, e á Agricultura, que desde então principiarão a progredir, e florescer." 16

Um ano depois de voltar para Lisboa, Domingos Vandelli morre, deixando ainda a família em difícil situação financeira, como atesta carta da viúva Feliciana Vandelli com requerimento encaminhado ao Brasil em 11 de fevereiro de $1817 .{ }^{16}$ Em outro documento de 1819, Feliciana Vandelli descreve que já recebia pensão no valor da metade do ordenado do marido como ex-Diretor do Real Museu e do Jardim Botânico da Ajuda. Solicita, contudo, também uma pensão ao seu filho mais moço Francisco Vandelli, assim como para a filha Maria Luiza, além dos serviços do finado marido para o filho mais velho Alexandre Vandelli. ${ }^{16}$

Após a morte de Domingos a presença de José Bonifácio foi importante para Alexandre Vandelli e toda a sua família, em termos sociais e financeiros, pelo menos até o casamento de 1819. José Bonifácio, além de renomado naturalista, já granjeara a reputação de defensor da Pátria portuguesa, tendo pegado em armas durante as invasões francesas a Portugal.

Durante a conturbada década de 10, mais precisamente desde 11 de agosto de 1813, Alexandre Vandelli tornou-se Assistente de José Bonifácio no Laboratório Químico da Casa da Moeda de Lisboa. ${ }^{17}$

Nessa época, Bonifácio publica a memória de metalurgia intitulada "Sobre Minas de carvão e ferrarias de Foz do Alge, em Portugal". Este trabalho foi publicado no jornal "O Patriota" do Rio de Janeiro (1813), e também em Londres. Na cidade londrina saiu em três números diferentes do periódico "O Investigador Portuguez em Inglaterra" ${ }^{18}$ 
Em 1814, José Bonifácio, Sebastião Francisco de Mendo Trigoso, João Croft e Bernardino Antonio Gomes publicam nas Memórias de Matemática e Física da Academia Real das Ciências de Lisboa suas "Experiências Chymicas, Sobre a Quina do Rio de Janeiro comparada com outras". ${ }^{19}$ Neste trabalho químico está registrado o papel de Alexandre Vandelli, cuja participação está descrita na primeira página do texto:

"Este Laboratório munido de todos os vazos e utensilios, que lhe são proprios; tinha comtudo falta de muitos reagentes, principalmente d'aqueles que mais se alterão, os quaes seriamos obrigados a preparar; a não ser a franqueza do $\mathrm{Sr}$. Alexandre Antonio Vandelli, que alem de nos ajudar com o seu trabalho, nos forneceo os que nos forão necessarios, $e$ ainda outros de que carecia o sobredito Estabelecimento. " 19

Ainda na função de Assistente de Bonifácio, Alexandre Vandelli trabalhou na Intendência Geral de Minas e Metais do Reino até 1819. Com a vinda do sogro para o Brasil no mesmo ano, passa a ocupar interinamente a direção da mesma Intendência, assim como da Real Ferraria da Foz do Alge e das Minas de Carvão de Buarcos. ${ }^{20}$

Em 1824 foi substituído pelo Barão de Eschwege na Direção da Intendência de Minas e Metais. Dois anos antes, porém, Alexandre Vandelli assumiu a função de Guarda-Mor dos Estabelecimentos da Academia Real das Ciências de Lisboa, da qual já era sócio desde 1805. ${ }^{21}$ Esta ligação com a Academia se manteve mesmo depois de sua transferência para o Brasil, quando ele passou a sócio-correspondente até sua morte.

O Museu da Academia das Ciências de Lisboa possui hoje, em sua seção de paleontologia, peças e objetos devidos a João da Silva Feijó, ao Barão Ludwig von Eschwege e a Alexandre Antonio Vandelli, especialmente na subseção de vertebrados. ${ }^{22}$ A pesquisa de fósseis ictiológicos em Portugal se iniciou de forma realmente sistemática com Alexandre Vandelli e Ludwig von Eschwege, sendo que o primeiro estudou e registrou restos de cetáceos e de peixes miocênicos, classificados com boa aproximação, quando ainda Guarda-Mor da Academia. ${ }^{23}$ Por esta razão, Alexandre Vandelli é hoje considerado um dos fundadores da paleontologia portuguesa.

Alexandre propôs, como se lê no discurso da sessão pública da Classe de Ciências Naturais de 19 de dezembro de 1831 (registrado no Tomo XI das "Memórias"), que a Academia desenvolvesse um Gabinete de máquinas voltadas para o estímulo da indústria no país. Alexandre Vandelli procurou também reorganizar o Museu da Academia das Ciências, local que contava com muitas peças. Havia na época a necessidade de se organizar o material que a Academia possuía. Seu próprio pai havia deixado objetos e material escrito desde Coimbra, assim como material coletado e enviado por seus alunos viajantes (entre eles Alexandre Rodrigues Ferreira em sua famosa Viagem Filosófica à Amazônia e ao Centro-Oeste brasileiro no período 1783-1792). Alexandre Vandelli, de posse de parte desse e de outros materiais, doou manuscritos do pai para enriquecimento da Biblioteca da Academia. ${ }^{24}$

Anteriormente, ainda em 1812, tornou-se membro-ajudante da Comissão de Reforma dos Pesos e Medidas, criada com o intuito de uniformizar o padrão de medidas em Portugal. Dois anos mais tarde o Príncipe Regente D. João aprovou a proposta dessa Comissão, baseada no sistema métrico francês, passando-se a produzir em Portugal os novos padrões de pesos e medidas para uso no Reino. Como era de se esperar, enquanto a Academia das Ciências e a Universidade de Coimbra absorveram as mudanças, este não foi o caso da população, em especial a do interior. Evitou-se, por exemplo, a utilização da palavra metro, entre outros motivos devido ao francesismo que evocava, sendo utilizada a expressão "mão-travessa" para a unidade fundamental. A “mão-travessa" correspondia ao decímetro (décima parte do metro). De igual forma, passou-se a utilizar o litro como unidade de volume, mas designando-o pelo antigo nome de "canada". A unidade de peso seria a libra, que correspondia a um quilograma. A adoção definitiva do sistema métrico decimal, com suas unidades e nomenclaturas, viria a ocorrer apenas em 1852, como prosseguimento dos trabalhos da Comissão Central de Pesos e Medidas. ${ }^{25}$

Além dos trabalhos científicos publicados tanto nas Memórias da Academia Real das Ciências de Lisboa, e dos manuscritos inéditos existentes no Brasil, Alexandre Vandelli deixou cinco obras maiores quando ainda estava em Portugal: Resumo da Arte de Distillação (1813), ${ }^{26}$ que foi impresso e distribuído gratuitamente pela Junta do Comércio, ${ }^{27}$ do qual fazia parte como ajudante; Zoologia Portuguesa (1817) em dois volumes manuscritos, ${ }^{28}$ transcrevendo informações zoológicas antigas e contemporâneas, inclusive do naturalista brasileiro Alexandre Rodrigues Ferreira; Ensaio sobre a Nomenclatura Vulgar e Trivial, e Sinonímia Zoologica Portugueza (1817), manuscrito que discorre sobre vários animais do Reino português; $;{ }^{29}$ Apontamentos para a História das Minas de Portugal, Colligidos pelo Ajudante, servindo de Intendente Geral das Minas e Metais do Reino (1824), ${ }^{30}$ além da Collecção de Instruções sobre a Agricultura, Artes e Industria (1831-1832). ${ }^{31}$

Alexandre Vandelli dirigiu em Lisboa uma fábrica de azulejos, situada na região do Rato da capital portuguesa. Chamava-se Real Fábrica de Louça (do Rato) de Lisboa, e existiu entre os anos de 1767 a 1835. Ela começou a funcionar tendo como administrador Tomaz Brunetto até 1771, altura em que foi substituído por Sebastião Inácio de Almeida. Inicialmente a fábrica produziu peças de grande qualidade, algumas das quais foram encomendadas pelo próprio Marquês de Pombal. Em 1818, Alexandre Vandelli assumiu a direção da fábrica. Não conseguiu conduzir tranquilamente a sua gestão sem ser influenciado pelos problemas políticos e financeiros do país, o que fez a fábrica passar por sucessivas crises que culminaram no seu encerramento em $1835 .{ }^{32} \mathrm{~A}$ família Vandelli tinha, desde o pai, a tradição de trabalhar com louças de grande qualidade. Domingos Vandelli achava a argila da região de Coimbra, onde viveu, de grande valia para a cerâmica. Nesta cidade montou uma pequena fábrica em 1784, criando um novo tipo de faiança coimbrã, cujos produtos vieram a ser conhecidos mais tarde por "louça de Vandel" (ou "de Vandelli”, “de Vandelles”). Possuíam grande finura e delicada pintura.

Em 1833 Alexandre foi acusado de suposto apoio aos absolutistas que, no mesmo ano, perderam a disputa pelo poder português para D. Pedro IV, decidindo então vir para o Brasil com a família. As dificuldades políticas e materiais pelas quais Alexandre Vandelli passou parecem ter marcado, desde jovem, um estilo direto e quase rude na relação com aqueles com quem não concordava, como aconteceu com o Barão de Eschwege e os alemães empregados na Ferraria do Alge em Portugal. E também com Francisco Freire Allemão de Cysneiros e Frederico Leopoldo Cezar Burlamaque, anos depois no Rio de Janeiro, quando da formação da Sociedade Vellosiana de Ciências Naturais. As inúmeras querelas nas quais Vandelli se envolveu no Brasil serão bem exemplificadas quando da questão dos nevoeiros secos do Rio de Janeiro, o que se discutirá mais à frente neste artigo.

\section{A FASE BRASILEIRA}

Custeado por José Bonifácio, ${ }^{33}$ chegou Alexandre Vandelli com toda a família à cidade de Santos em 1834, tornando-se um pequeno negociante até 1837/38, como mostra o censo realizado em Santos e demais localidades de São Paulo neste último ano. Este censo é considerado um dos melhores e mais completos realizados na Província de São Paulo durante o século XIX. ${ }^{34}$ Consta neste documento que Alexandre possuía apenas um escravo, o que denotava situação 
humilde frente aos fazendeiros e produtores da época. ${ }^{35}$ Alexandre Vandelli chegou ao Brasil em uma época ao mesmo tempo importante, dramática e tumultuada da história brasileira: o período regencial (1831-1840). O país vivia entre as idéias revolucionárias que pendiam entre um liberalismo monárquico e outro de tendências mais exaltadas e republicanas, em oposição a uma terceira via dos mais ferrenhos monarquistas. Revoltas explodiam em vários lugares. ${ }^{36} \mathrm{~A}$ ciência ficou, por algum tempo, parcialmente adormecida para Vandelli.

Em 1838, porém, José Bonifácio faleceu em Niterói, o que pode ter influenciado de alguma forma a não permanência de Alexandre Vandelli e da família em Santos. Entre 1837/1838 retomara as atividades de naturalista, sendo nomeado pelo Presidente da Província de São Paulo, Gavião Peixoto, Diretor de uma escola de agricultura na capital denominada de Fazenda Normal. Esta foi criada numa antiga fazenda jesuíta de nome Sant' Anna na capital paulista. A Fazenda se destinava ao ensino e desenvolvimento das técnicas básicas na área da botânica, química e agricultura, tendo o modelo sido utilizado também no Jardim Botânico do Rio de Janeiro a partir do mesmo ano de $1838 .{ }^{37}$

A distância da Corte provavelmente dificultava também o sucesso profissional e financeiro de Vandelli, o qual veio para o Rio de Janeiro ao final do ano de $1838,{ }^{38}$ como mostram seus registros de naturalização no Arquivo desta cidade e sua posterior atividade no Palácio da Quinta da Boa Vista como Mestre da Família Imperial. ${ }^{39}$

Pouco depois da inauguração do Colégio Pedro II, Alexandre Vandelli foi encarregado em 1839 de escolher nas coleções de Botânica e Mineralogia do Museu Nacional um conjunto de exemplares para servir ao curso de ciências daquele estabelecimento. ${ }^{40} \mathrm{Em} 15$ de março de 1839 é feita a entrega ${ }^{41}$ Alexandre, contudo, nunca lecionou no colégio.

Enquanto Mestre, Alexandre Vandelli foi professor de Botânica e Princípios de Ciências Naturais do jovem Imperador D. Pedro II e de outros membros da família Imperial, ininterruptamente, de 01 de dezembro de 1839 a (pelo menos) março de $1862 .{ }^{40}$ Ele fora nomeado inicialmente pelo segundo tutor de D. Pedro II, o Marquês de Itanhaém, que sucedera a José Bonifácio nessa função em fins de 1833. A partir de várias fontes, como documentos constantes do Arquivo Nacional, pode-se presumir que Vandelli tenha ao final de sua vida ministrado aulas também às filhas de D. Pedro II. ${ }^{42}$ Isto seria natural, levando-se em conta que alguns outros membros da Sociedade Vellosiana também o fizeram. ${ }^{43}$

Com sua notoriedade no meio científico e sua proximidade à família imperial, Vandelli tornou-se Comendador da Ordem da Rosa em 02 de dezembro de 1841 por decreto de D. Pedro II. ${ }^{44}$

Vandelli também atuou como fiscal ${ }^{45}$ do Imperial Núcleo Hortículo Brasiliense entre os anos de 1856 e $1859 .{ }^{46}$ Esta Instituição, segundo seus estatutos, visava a incrementar e orientar a botânica. O Núcleo foi fundado em 1849 por José Praxedes Pereira Pacheco, ficando sob a proteção do Imperador a partir desse mesmo ano. ${ }^{47}$ Praxedes era pessoa polêmica, com escritos que misturavam todos os assuntos que podia, tais como poesia, geografia, botânica, letras, comportamento social etc..$^{48}$

Alexandre Vandelli foi um dos doze sócios efetivos fundadores da Sociedade Vellosiana de Ciências Naturais do Rio de Janeiro, ${ }^{49}$ criada oficialmente em 22 de outubro de 1850 com a finalidade, segundo o artigo $1^{\circ}$ de seus Estatutos, de "indagar, collegir, e estudar todos os objectos pertencentes à História Natural do Brasil; e juntamente averiguar, e interpretar as palavras indigenas, com que forem designados" ${ }^{50}$ Alexandre Vandelli, Freire Allemão e os demais fundadores desejavam incentivar com tal iniciativa a pesquisa de temas científicos nacionais. ${ }^{51}$ No início de funcionamento da Sociedade os sócios efetivos foram distribuídos em quatro Seções, sendo estas consideradas permanentes: Etnografia, Zoologia, Botânica e Geologia e Ciências
Físicas. Alexandre Vandelli ligou-se à seção de mineralogia, sendo esta composta também por Frederico Leopoldo Cezar Burlamaque, Cândido Teixeira de Azeredo Coutinho e Custódio Alves Serrão. ${ }^{52}$

Na sessão de 08 de agosto de 1851, Freire Allemão propôs a criação de outras quatro Comissões que enfatizavam ainda mais a proposta de criação de uma Sociedade científica nacional. Alexandre Vandelli, o próprio Francisco Freire Allemão, Frederico Leopoldo Cezar Burlamaque e Joseph Théodore Descourtilz deveriam compor um catálogo cronológico de todos os autores nacionais ou estrangeiros que, diretamente ou não, tivessem deixado algum escrito sobre a História Natural do Brasil, inventariando as respectivas obras produzidas. ${ }^{53}$

A Sociedade Vellosiana passou por muitos problemas, com inúmeras competições internas, ressentindo-se da falta de participação e apoio do Imperador D. Pedro II (assíduo frequentador de reuniões intelectuais e científicas, nunca prestigiando, porém, os encontros da Sociedade Vellosiana). Entre os próprios membros da Sociedade surgiram constantes dissensões internas que resultaram em seu adormecimento contínuo e gradual. Apesar de o fim das atividades ser normalmente apontado como o ano de $1852,{ }^{54}$ os registros das Atas manuscritas do Arquivo do Museu Nacional e do Almanak Laemmert mencionam reuniões esporádicas pelo menos até 1857 , seguindo-se atas até 1870 .

\section{Trabalhos científicos publicados por Alexandre Vandelli}

Nos escritos de Alexandre Vandelli verifica-se que termos excessivamente técnicos e científicos das muitas áreas científicas que abrangeu são transpostos para uma linguagem de maior acessibilidade, o que deixa antever o sentido utilitário e pragmático do seu discurso científico. A ciência faz-se na época para ser útil, tendo que chegar às camadas de pessoas de atividades mais técnicas, como os que trabalhavam com a química e a agricultura. É uma ciência feita e desenvolvida para conter aplicações, comprovando o serviço que presta a todas as camadas sociais e também nos negócios correntes.

No século XIX proliferaram as enciclopédias populares, os dicionários metódicos, os manuais e compêndios de sistematização, os jornais e revistas de divulgação, os almanaques de natureza diversa e os catecismos que transmitem as boas novas científicas. Vandelli está, então, inserido neste contexto com seus trabalhos.

Alexandre Vandelli atuou nas mais diversas áreas do saber ilustrado no século XIX, como se comprova nos seus trabalhos. Seus textos e preocupações técnicas e científicas abrangem principalmente Química, Mineralogia, Geologia, Agricultura, Paleontologia, Zoologia, Botânica, Meteorologia. Todavia, sua atuação tanto no Brasil quanto em Portugal ultrapassou estes limites, já que participou da administração e fabricação de louças (seguindo a tradição iniciada com seu pai, como já dito), assim como atuou na administração pública, na fabricação e fundição de produtos de ferro, extração de carvão, além da área educacional. Sua atividade como educador pode ser acompanhada, por exemplo, na folha de pagamentos dos Mestres da Família Imperial entre 1839 e $1862 . .^{55}$

Na Química, Alexandre Vandelli produziu em Lisboa, no ano de 1813, uma obra de 82 páginas intitulada "Resumo da arte de Distillação". ${ }^{27}$ Impressa por conta da Junta de Comércio, onde seu pai também trabalhava, foi distribuída gratuitamente. $\mathrm{O}$ tema da destilação de aguardente, problema central no livro, era muito importante para Portugal na época e foi objeto de muitos trabalhos também de químicos franceses (Vandelli cita, por exemplo, Lavoisier e Chaptal). Alexandre também demonstra conhecer o livro do brasileiro João Manso Pereira, intitulado "Memória sobre a reforma dos alambiques", que fora publicado em Lisboa no ano de $1797 . .^{56}$

Vandelli menciona a necessidade da modernização em Portugal dos alambiques, devido à mistura dos bons e maus tipos existentes 
(inclusive para se evitar danos à saúde), além da importância econômica que tal produção exerceria na época. Na Introdução da obra, Vandelli deixa uma clara mensagem de seu pensamento utilitarista para a Química:

\begin{abstract}
"A arte de distillar tem grangeado hum geral acolhimento nos paizes industriosos, assim como pela consideração dos Governos, como pela dos homens sábios; (a) aquelles a tem olhado como hum interessante ramo de commercio, $e$ de industria, e como productora de hum genero, que se tem tornado de primeira necessidade;..." 27
\end{abstract}

E na nota (a) de pé de página acrescenta:

"Tudo o que pertence á Arte da distillação (diz Chaptal Ann. de Chim. T. 69) tudo o que tende a aperfeiçoar os processos, merece huma particular attenção da parte das pessoas... se interessão nos progressos das Artes..." 27

Fica clara a preocupação de Alexandre em preservar a "Arte" (e os "Artistas", como diz na pág. 6), ${ }^{57}$ sendo a palavra "Arte" aqui empregada na acepção da época, ou seja, enquanto produto do engenho humano com interesse científico e econômico para a sociedade. Esta foi uma marca recebida da época de seu pai, que exerceu sempre em todas as suas atribuições a função proposta pelo iluminismo: aqueles que possuíam determinado saber, como a Química, deveriam transformar o conhecimento em técnica para o bem da pólis. A técnica submete-se à razão também em Portugal. Alexandre Vandelli cita a Inglaterra várias vezes no texto como aquela nação que recompensa os que buscam os progressos nas Artes, justificando assim estar aquele país à frente de Portugal.

Vandelli buscou no texto introduzir novamente em Portugal a discussão de novos formatos para os alambiques, de modo a otimizar a produção e evitar um possível envenenamento com a formação de acetato de cobre. ${ }^{58}$

O artigo "Experiências Químicas sobre a Quina do Rio de Janeiro Comparada com Outras" foi escrito em 1811 por José Bonifácio, Sebastião Francisco de Mendo Trigoso, João Croft e Bernardino Antonio Gomes. ${ }^{19}$ Vandelli participou no preparo dos vários reagentes químicos utilizados para verificar se a quina do Rio de Janeiro era de boa qualidade, uma vez que ela era produto natural de grande interesse estratégico e militar na época. ${ }^{59}$ Este texto se completa com outro estudo químico publicado em 1818 nas mesmas "Memórias da Academia" e de autoria exclusiva de Vandelli, intitulado "Experiências sobre duas differentes cascas do Pará", analisando a composição física e química de cascas de plantas brasileiras. Vandelli inicia seu trabalho a partir do fato de que o Delegado do Físico-Mor do Exército recebera 40 arrobas "de duas differentes Cascas amargas do Pará para o uso dos Hospitaes militares,...". ${ }^{60}$

A quina era importante no tratamento contra febre intermitente, malária, feridas e inflamações. Ela era o principal febrífugo da época e de uso difundido nas armas da Corte, pois não havia muitos tratamentos específicos em ferimentos de guerra. Assim, saber se a qualidade da matéria prima - as cascas - que eram usadas em Portugal e no Brasil era de boa qualidade possuía forte interesse estratégico e econômico.

Meia arroba de cada tipo de casca do Pará foi enviada ao Laboratório Químico da Casa da Moeda para análise de Alexandre, sendo as amostras chamadas de "N.1" e "N.2". Vandelli analisou cor, sabor, cheiro, fraturas, porosidade das cascas, através de macerações e decocções com solventes. Comparou as cascas do Pará com a quina do Rio de Janeiro, e com a quina amarela (de que se usavam as folhas e cascas e era muito comum no Peru, controlado pelos espanhóis). ${ }^{61}$
Concluiu que a casca do Pará "N.1" era quina verdadeira. Afirma ele que esta quina e a do Rio de Janeiro contêm os mesmos princípios e utilidades. Em relação à análise química da amostra em infusão da casca N.2, esta só altera a cola, que ele afirma precipitar nos exames de laboratório, mas teria também os mesmos resultados ativos da quina fluminense.

Um artigo em Física foi proposto por Vandelli: "Memória sobre a gravidade específica das águas de Lisboa e seus arredores", publicado em 1812 nas "Memórias Econômicas" da Academia Real das Ciências, Tomo IV. ${ }^{62}$ Este é um trabalho realizado a partir do conceito físico de gravidade específica de um sólido de latão de uma polegada cúbica, utilizando-se água destilada como padrão para se comparar com as águas de várias fontes de Lisboa e arredores: chafarizes, águas livres, bicas, minas e poços. ${ }^{63} \mathrm{O}$ resultado apresenta as amostras de água separadas, discriminando a região. Novamente surge a questão econômica, pois nos corolários escreve:

"Como é mais proveitosa na economia animal aquela água que pesa menos, por ser mais pequeno o número de corpos heterogêneos, que tem dissolvidos; por isso se devem escolher para o uso económico as menor gravidade específica." 62

E continua:

"E os Artistas, com especialidade os tintureiros, que têm de fazer uso das águas mais puras, principalmente para o cozimento, e desengomado das sedas com o sabão, e para a desengorduragem das lãs pelos álcalis, poderão regular-se por esse exame." ${ }^{2}$

Alexandre termina seu texto com uma tabela em ordem nominal e crescente de gravidade específica das amostras, apresentando a temperatura da água da maioria delas.

Alexandre Vandelli também deixou um grande número de manuscritos inéditos, dos quais nos ocuparemos agora. Um deles é intitulado "Reflexão sobre a questão dos nevoeiros seccos da atmosfera do Rio de Janeiro. Apresentada na Sociedade Vellosiana, pelo Snr. Dr. Francisco Freire Allemão. 13 de nov. de 1853. Carta a D. Pedro II". ${ }^{64}$ Este é um texto longo, no qual Vandelli procura rebater as idéias de Francisco Freire Allemão de Cysneiros e de Frederico Leopoldo César Burlamaque a respeito da origem dos nevoeiros secos que costumavam cobrir o Rio de Janeiro, principalmente entre os meses de agosto e setembro. O Arquivo do Museu Imperial de Petrópolis conserva este manuscrito inédito datado de 13 de novembro de 1853. O manuscrito foi presenteado por ele a D. Pedro II, constando de três partes, datadas de 16 de abril, 24 de novembro e 10 de dezembro de 1853 , respectivamente. São no total 41 páginas manuscritas em letra uniforme e legível, muito diferente da grafia de Vandelli. ${ }^{65}$ A terceira parte é intitulada "Aditamento", tendo sido composta após a carta de dedicação ao Imperador.

Inicialmente, para Freire Allemão (a partir de dois trabalhos publicados na revista Guanabara) a névoa que cobria a cidade do Rio de Janeiro entre julho-agosto e outubro era principalmente oriunda das queimadas muito comuns na época. Burlamaque discordou de Freire Allemão em outro texto (na mesma revista) de que a causa fossem as queimadas, porém, não ofereceu claramente uma solução. ${ }^{66}$ Já Alexandre Vandelli propôs que as névoas seriam relacionadas a fenômenos atmosféricos e astronômicos. Ou seja, uma explicação completamente diferente, apesar de ainda em voga na época, da influência cósmica na atmosfera terrestre. ${ }^{67}$

Este é um trabalho no qual Alexandre Vandelli atacou, de forma virulenta, seus dois debatedores, mostrando as desavenças que ocorriam no seio da Sociedade Vellosiana presidida por Freire Allemão. 
Problemas pessoais que, certamente, contribuíram para o adormecimento da Sociedade ao longo da década de 50 do século XIX.

Em 1847 Frederico Burlamaque também entrou em outra disputa com Alexandre Vandelli, desta vez para o cargo de Diretor do Museu Nacional em substituição ao frei carmelita Custódio Alves Serrão. ${ }^{68}$ No documento encontrado na Biblioteca Nacional/RJ há uma carta na qual "o Dr. Burlamaque, Alexandre Antonio Vandelli e o Dr. Emilio Germon são os pretendentes ao cargo". O vencedor na disputa foi Burlamaque, que ficou na direção de 1847 a 1866, tendo executado reputada administração.

Vandelli legou-nos ainda algumas publicações mineralógicas e geológicas importantes para a ciência portuguesa. Como mencionado antes, sua obra de 28 páginas intitulada "Additamentos ou nota à Memória geognóstica ou golpe de vista do perfil das stratificações das diferentes rochas que compõem os terrenos desde a serra de Cintra até a de Arrabida", foi publicada em 1831 nas Memórias da Academia Real das Ciências de Lisboa. Trata-se de um extenso trabalho que se combina com outro anterior no mesmo tomo do Barão de Eschwege, e em que se mostram pranchas estratigráficas das localidades. $\mathrm{O}$ texto vandelliano e suas pranchas, mostrando com detalhes os fósseis vertebrados marinhos, é considerado o marco inicial da paleontologia dos vertebrados em Portugal.

No que tange a situação mineralógica de Portugal na época de Vandelli (início dos oitocentos), temos os "Apontamentos para a história das minas de Portugal, colligidos pelo ajudante, servindo de intendente geral das minas e metaes do Reino", publicado em Lisboa em $1824 .{ }^{69}$ Este opúsculo foi o resultado de suas experiências metalúrgicas em Portugal, tanto na Intendência Geral de Minas e Metais quanto na direção da Real Ferraria da Foz de Alge desde a década de 10 do século XIX.

Vários problemas surgiram e impediram o desenvolvimento da indústria mineira em Portugal no período de transição do Antigo Regime ao Liberalismo. Eram questões de ordem política, institucional, financeira e técnica. Através do trabalho de José Bonifácio e Alexandre Vandelli na Intendência Geral de Minas se pode mapear as dificuldades daquele país na área, facilitando o entendimento historiográfico dos motivos que levaram Portugal a vir pesquisar no Brasil a possibilidade de encontrar minas produtivas. Mesmo até pouco tempo antes da Independência brasileira em 1822.

Nos "Apontamentos para a história das minas de Portugal" Alexandre Vandelli mostra, por exemplo, o caso das Ferrarias da Foz do Alge e os problemas administrativos que lá surgiram. Há o registro das contradições e tensões do trabalho com os alemães, contratados supostamente para acelerar o desenvolvimento mineralógico do país, fato que para o autor não ocorreu. $\mathrm{O}$ ponto de partida para a modernidade, e que poderia representar um processo de liberalização política português, defrontou-se neste caso com problemas próprios de um país dissonante. Alexandre Vandelli sabia que Portugal deveria seguir para uma postura industrial, e que a ausência de uma atividade mineira regular preexistente eliminaria as chances de Portugal crescer economicamente.

Alexandre Vandelli deixou algumas obras sobre zoologia. Com um vasto Reino natural em seu poder, a elite intelectual lusa percebeu que deveria conhecê-la melhor antes que outros o fizessem. Uma das obras de Alexandre mais importantes para a compreensão da pesquisa naturalista até o início do século XIX chama-se "Zoologia portugueza". ${ }^{70}$ Trata-se de um manuscrito de 1817 , com 1.454 páginas, composto em Lisboa como primeiro volume de uma coleção por ele elaborada. Descreve o conteúdo de várias dezenas de outras obras (particularmente desde o século XVII) e de muitos autores anteriores à sua própria geração, ocupando-se em boa parte da descrição de animais brasileiros. Entre os autores citados destacamos a cópia de trabalho de Alexandre Rodrigues Ferreira na página 156, com longo título: "Relação - Dos animaes quadrúpedes silvestres que habitão nas matas de todo o continente do estado do grão Pará, divididos em tres partes: $1^{a}$ dos que se apresentão nas mezas por melhores: $2^{a}$ dos que comem os Índios em geral, e alguns Brancos quando andão em diligencias pelo sertão: $3^{a}$ dos que se não comem". ${ }^{71}$ Neste trabalho e em alguns outros do mesmo volume surgem nas margens anotações originais de Alexandre Vandelli, com referências a nomes científicos dos animais citados.

$\mathrm{O}$ "Extracto de 88 autores para a nomenclatura zoológica portugueza", 72 cujo subtítulo é "Extraído de 63 autores", foi também manuscrito e datado de 1817, redigido em Lisboa, sendo o segundo volume do manuscrito anterior. Neste volume Alexandre Vandelli disserta largamente sobre vários animais brasileiros e portugueses (assim como na obra "Ensaio sobre a Nomenclatura Vulgar e Trivial, e Sinonímia Zoologica Portugueza"), mostrando a importância do conhecimento zoológico do Reino. E como fez seu pai em seus trabalhos e no planejamento das viagens dos naturalistas-viajantes.

Segundo as Atas da Sociedade Vellosiana, Alexandre Vandelli teria doado ao mesmo tempo dois outros manuscritos originais e inéditos, sem menção de data, redigidos por ele sobre zoologia. $\mathrm{O}$ objetivo era a constituição de um acervo para aquela Instituição. Foram eles: "Extractos sobre a nomenclatura Ichtyologica", e o "Discurso sobre a nomenclatura vulgar e trivial portugueza, que deve ser preferida á que se usa na traducção portugueza de Cuvier". ${ }^{73}$

Alexandre Vandelli mostrou-se sempre preocupado com o legado histórico que marcava as ciências dos países que viveu. Em 1851, no Rio de Janeiro, escreveu em 12 páginas o manuscrito "Retoques e rectificações a alguns elogios insertos na Revista do Instituto Histórico e Geográfico Brazileiro", tomos $1^{\circ}$ e $2^{\circ} .{ }^{74}$ Defendia ardorosamente a memória de seu pai Domingos Vandelli, segundo ele esquecido injustamente por todos, apesar de tudo o que fez por Portugal. Por outro lado, outras personalidades seriam sempre lembradas. Alexandre as considera de muito menor vulto para a história e as ciências lusobrasileiras. O resultado da discrepância de tratamento, para Alexandre, estaria nos aduladores do poder que preferiam enaltecer os alunos (que inscreveram seu nome na história graças principalmente a seu pai) aos verdadeiros mestres estrangeiros. Em algumas partes do texto ele também defende o mestre italiano de Física de Coimbra, o naturalista estrangeirado Dalla Bela, que veio da Itália com seu pai quando da reforma pombalina do século XVIII.

Alguns dos nomes mencionados no texto são os de José da Silva Lisboa (Visconde de Cairú), Balthasar da Silva Lisboa, Martinho de Mello e Castro (Ministro de Estado), Alexandre Rodrigues Ferreira. ${ }^{75}$

Em outro texto histórico de Alexandre Vandelli, intitulado "Refutação da Memória: Onde aprenderam e quem foram os artistas que fizeram levantar os templos dos jesuítas em Missões, etc. inserta na revista do IHGB" ${ }^{78}$ Alexandre irá refutar a proposição histórica do trabalho do Desembargador Silva Pontes publicado em 1842 na Revista do Instituto Histórico e Geográfico Brasileiro. ${ }^{76}$ Silva Pontes afirmara terem sido os jesuítas os responsáveis por levar para o Japão não apenas a civilidade, mas também a imprensa, pela qual se estamparam os livros de instrução religiosa e moral. Alexandre Vandelli discordou, discorrendo que os japoneses e orientais já eram suficientemente organizados há muito mais tempo que a história européia queria crer, possuindo a técnica da impressão antes mesmo de lá chegarem os jesuítas e de Gutemberg. Segundo ele, a cultura japonesa em especial mostrara que não dependeu da inserção ocidental para desenvolver-se na escrita.

Alexandre Vandelli percebia que a educação no Brasil, em especial a educação técnica, não seguia adiante como se faz necessário em uma nação que necessitava (como acontecia com Portugal quando lá estava) crescer e produzir, competindo assim com as nações "industriosas" da França e da Inglaterra. Redige, por isso, o texto "Ingênuos 
reparos e reflexões sobre o projecto de um estabelecimento agrícola, formulado pelo gymnasio brasileiro", escrito no Rio de Janeiro em $1850 .{ }^{77}$ Trata-se de um manuscrito de 19 páginas, no qual ele expõe extensamente suas criticas à forma com que a educação agrícola, tão importante a qualquer país em sua opinião, estava sendo proposta pelo Ginásio Brasileiro. Além da sua experiência anterior na direção da Escola Normal de São Paulo, mais uma vez Vandelli mostra a influência de sua formação com seu pai e José Bonifácio, denotando seu espírito fisiocrata e um utilitarismo. A construção do prédio agrícola estaria sendo muito mal gerida e se tornaria inoperante, gerando altos custos para a administração pública e sem conseguir a eficácia técnica desejada.

Dentro do mesmo espírito, Alexandre Vandelli publicara em Lisboa entre os anos de 1831-1832, através da Typographia da Academia Real das Ciências, uma coletânea de opiniões a respeito da produção técnica e científica em Portugal das primeiras décadas do século XIX. A obra chamou-se "Collecção de Instruções sobre a agricultura, artes e industria". Neste texto Vandelli mostra o que seria o caminho para o desenvolvimento mais rápido de Portugal através da razão aplicada às artes em geral, à agricultura e à indústria. $\mathrm{O}$ texto foi compilado a partir de trabalhos da própria Academia de Ciências, da qual ele era Guarda-Mor na época, além de outros que lá chegavam de Academias internacionais.

\section{CONCLUSÃO}

Alexandre Antonio Vandelli atuou nas mais diversas áreas do saber no século XIX, sendo sua atuação em Portugal marcada por importantes feitos, tais como o Gabinete de máquinas da Academia das Ciências de Lisboa e o início sistemático da Paleontologia dos vertebrados.

A mineração portuguesa deve-lhe as inúmeras tentativas de continuar o projeto iluminista de José Bonifácio de um Portugal independente nesse setor econômico, sendo uma de suas principais características o nacionalismo científico. Alexandre e o sogro tinham plena consciência de que o país teria que entrar definitivamente na proposta liberal inglesa da revolução industrial. Para isso, todas as áreas em que a família Vandelli atuou foram importantes. As obras e as várias cartas depositadas na Biblioteca Nacional do Rio de Janeiro deixam entrever a opinião vandelliana de que Portugal não necessitava dos serviços e da intelectualidade de estrangeiros que nada traziam ao país. Seu maior foco de ataque foram os alemães, estrangeiros comumente importados pela administração da Intendência das Minas visando impulsionar e prosperar as várias minas que Portugal possuía.

Com a independência e os vários movimentos que constituíram a história da nação brasileira, o Rio de Janeiro através de sua capitalidade passou a ser o local de atuação deste químico e proeminente naturalista. Foi um dos mestres que ajudaram a despertar no jovem Imperador D. Pedro II o reconhecido gosto pelas ciências, prazer que sempre acompanharia o monarca pelo resto de sua vida.

Através da Sociedade Vellosiana de Ciências Naturais do Rio de Janeiro nosso personagem participou da importante tentativa de estabelecer um grupo científico de cunho estritamente brasileiro. Travou com Francisco Freire Allemão de Cysneiros e Frederico Leopoldo Cesar Burlamaque a mais interessante das discussões que lá surgiram (quanto aos nevoeiros secos da cidade do Rio de Janeiro).

O químico e naturalista Alexandre Antonio Vandelli traz consigo a tentativa de sobrevivência de uma concepção iluminista e fisiocrata de nação e de cidadania. Tentou manter acesa, até sua morte, a herança intelectual da família e da mente portuguesa, em que a razão deveria perpassar todos os ramos do viver e do saber. Para ele, acreditar no aperfeiçoamento racional dos homens, sobretudo em novos países, como o Brasil, era essencial para se atingir a concretização do progresso e do desenvolvimento.

\section{AGRADECIMENTOS}

Ao Prof. Manuel Carlos Serrano Pinto da Universidade de Aveiro pela obtenção de referências conservadas em Portugal.

\section{REFERÊNCIAS E NOTAS}

1. Ferraz, M. H. M.; Quim. Nova 1995, 18, 500.

2. Filgueiras, C. A. L.; Quim. Nova 1986, 9, 263.

3. Barreto, A.; Filgueiras, C. A. L.; Quim. Nova 2007, 30, 1780.

4. Torre do Tombo, Livro XI dos Matrimônios da Paróquia de Santa Isabel Rainha de Portugal, fls. 193, apud Fonseca, G.; A Revolução Francesa e a Vida de José Bonifácio - uma Interpretação Incômoda, EDART: São Paulo, 1968, p. 212.

5. Ref. 4, p. 213: mais particularmente no $\mathrm{n}^{\circ} 291$ desta rua, local no qual morou até vir para o Brasil em 1819. Alexandre Vandelli residia no $\mathrm{n}^{\circ} 123$.

6. Biblioteca Nacional/RJ, Setor de Manuscritos, cota ${ }^{\circ} \mathrm{I}-4,33,71$.

7. Arquivo Nacional. Cf. pasta de Ordens Honorificas - Ordem de Aviz, cx. 798, pac. 5, doc, com data de 17-06-1861.

8. Dados retirados do processo de naturalização de Alexandre Antonio Vandelli, localizado no Arquivo da Cidade do Rio de Janeiro, códice 43-1-78, pág. 9 (frente), e que são completados com o Juramento de naturalização constante no mesmo Arquivo sob o códice 18-1-61, pág. 11 (verso).

9. Biblioteca Nacional, Setor de Obras Gerais. Cf. microfilmes: P R C SPR01 - Jornal do Commercio, 14 de agosto de 1862, ano 37, anúncio na página 3. Informa que o cortejo fúnebre saiu da Rua do Engenho Velho, ${ }^{\circ}$ 47. PR-SPR 04, Diário do Rio de Janeiro - Folha Política, Llitterária, Commercial, edição de 16 e 17 de agosto de 1862, ano XIII, $\mathrm{n}^{\circ} 225,1^{\text {a }}$ página (obituário). PR-SPR01, Correio Mercantil, edição de 18 de agosto de 1862, ano XIX, página 2 (obituário). Alexandre Vandelli morreu viúvo, aos 78 anos, de gastro-entero-colite.

10. Em 1772 Domingos Vandelli havia sido feito doutor em Filosofia e Medicina na Universidade de Coimbra. Além de Catedrático, tornouse responsável também pela criação e direção do Jardim Botânico da Universidade.

11. As referências mais citadas e importantes que atribuem erradamente Lisboa como cidade natal de Alexandre Vandelli são: Sacramento Blake, A. V. A.; Diccionario Bibliographico Brazileiro, 1893, vol. 2, Imprensa Nacional: Rio de Janeiro; e Innocencio Silva, I. F.; Diccionario Bibliographico Portuguez, 1908, Imprensa Nacional: Lisboa, vol. II.

12. Declaração do próprio Alexandre Antonio Vandelli: ref. 8, códice $n^{\circ}$ 18-1-61, pág. 11 (verso). Quanto a sua origem coimbrã também é possível confirmar a mesma informação no Livro de Matrimônios de seu casamento com a filha de José Bonifácio (ref. 4).

13. http://www.triplov.com/hist_fil_ciencia/vandelli/meg.html, acessada em Julho 2007.

14. Sequeira, G. M.; Depois do Terramoto. Subsídios para a História dos bairros ocidentais de Lisboa, Academia das Ciências de Lisboa: Lisboa, 1967, II, 93-96.

15. Cf. cartas depositadas na Biblioteca Nacional/RJ, Setor de Manuscritos: C-0722,011, números 001 e 002, e C-81,42.

16. Carta de Feliciana Isabel Vandelli, Biblioteca Nacional/RJ, Setor de Manuscritos: C-0047, 016, e II-2,11,16.

17. Carvalho, J. S.; A Ferraria da Foz de Alge - Período de Alexandre António Vandelli (1819-1824), Estudos, Notas e Trabalhos do Serviço de Fomento Mineiro, Lisboa, 1954, IX, fasc. 1-4, p. 47.

18. Andrada e Silva, J. B.; Sobre Minas de carvão e ferrarias de Foz do Alge em Portugal, em Cerqueira Falcão, E.; Obras científicas, políticas e sociais de José Bonifácio de Andrada e Silva, Ed. Revista dos Tribunais: São Paulo, 1965, I, 109-130. Este trabalho de José Bonifácio foi composto em 1809 e publicado mais tarde tanto no periódico "O Patriota", do Rio de Janeiro, como em "O Investigador Portuguez" de Londres. 
19. Andrada e Silva, J. B.; Mendo Trigoso, S. F.; Croft, J.; Gomes, B. A.; Memórias de Mathematica e Physica da Academia Real das Sciencias de Lisboa, 1814, III, parte II, 96. Inserto em Cerqueira Falcão, E.; Obras científicas, políticas e sociais de José Bonifácio de Andrada e Silva, Ed. Revista dos Tribunais: São Paulo, 1965, III, 403.

20. Ref. 18 , p. 48.

21. No "Processo Alexandre António Vandelli", Fundos Documentais Série Azul, Biblioteca da Academia das Ciências de Lisboa, há um resumo histórico de sua passagem pela Academia: nomeado sócio correspondente em 06 de fevereiro de 1805; sócio livre em 08 de Abril de 1817; sócio substituto (de efetivo) em 26 de novembro de 1818; passando a sócio efetivo de $1^{\text {a }}$ classe de Ciências Naturais em 07 de abril de 1824. É possível acompanhar essa evolução também pelas atas da secretaria da Academia, que eram transcritas nos vários volumes das "Memórias" e "Memórias Econômicas". Nesta pesquisa foram usados os volumes do Setor de Obras Raras da Biblioteca Nacional/RJ: $\operatorname{cota}^{\circ}$ 97, 4, 01-15.

22. Antunes, M. T. Em História e desenvolvimento da ciência em Portugal; Antunes, M. T., org.; Publicação do II Centenário da Academia das Ciências de LIsboa, 1986, vol. II, p. 773-814.

23. Cf. História e Memórias da Academia Real das Sciencias de Lisboa, 1827, X, parte II, p. XXXVI, lê-se na "Lista dos Donativos" de 1830: "O Guarda-Mor dos Estabelecimentos. - Recolheu para o Museu varios Petrificados dos arredores de Lisboa, e alguns fosseis que trouxe da Villa das Caldas da Rainha."

24. Por exemplo, nas Memórias da Academia das Sciencias de Lisboa, 1819, VI, lê-se na p. XXI: "Também o Sr. Alexandre António Vandelli enriqueceu nosso Arquivo, consentindo que tirássemos uma cópia da correspondência epistolar dos Srs. Conde de Barbacena, Abade Correa com seu defunto pai e consocio Sr. Domingos Vandelli. São estas Cartas documentos preciosos para a história dos princípios da nossa Academia."

25. http://www.instituto-camoes.pt/cvc/ciencia/e36.html, acessada em Outubro 2009

26. Vandelli, A. A.; Resumo da Arte da Distillação, Officina de Simão Thaddeo Ferreira: Lisboa, 1813.

27. Segundo Francisco Santana, na Introdução à sua obra Documentos do Cartório da Junta do Comércio Respeitantes a Lisboa, Câmara Municipal de Lisboa, 1976, a Junta foi criada em 1755 (antes do terremoto que destruiu a cidade) e extinta em 1834 dentro da reestruturação da economia portuguesa, que organizava, entre outras funções, o comércio de material químico de Portugal e dos territórios ultramarinos.

28. Vandelli, A. A.; Zoologia portugueza. Manuscritos, Lisboa, 1817. Depositados na Biblioteca Nacional/RJ, Setor de Manuscritos, $\operatorname{cota} \mathrm{n}^{\circ}$ 03, 1, 009-010/011.

29. Vandelli, A. A.; Ensaio sobre a Nomenclatura Vulgar e Trivial, e Sinonímia Zoologica Portugueza, manuscrito depositado na Biblioteca da Academia das Ciências de Lisboa, 1817. Cota: Manuscritos da Série Azul n ${ }^{\circ} 345$.

30. Vandelli, A. A.; Apontamentos para a história das minas de Portugal, colligidos pelo ajudante, servindo de intendente geral das minas e metaes do Reino, $1^{\text {a }}$ parte. Lisboa, 1824. Localizado na Biblioteca da Academia das Ciências de Lisboa, s/n.

31. Vandelli, A. A.; Collecção de Instruções sobre a Agricultura, Artes e Industria, Typographia da Academia Real das Ciências: Lisboa, 18311832. Encontrado na Biblioteca Pública Municipal do Porto, $n^{\circ}$ U-2-65, Col. BPMP.

32. Sandão, A.; Faiança Portuguesa - Séculos XVIII-XIX, Companhia Editora do Minho: Barcelos, 1983.

33. Testamento de José Bonifácio, s.d., fac-símile do Setor de Manuscritos da Biblioteca Nacional/RJ: $\operatorname{cota}^{\circ} \mathrm{I}-4,34,063, \mathrm{n}^{\circ} 002$.

34. Microfilme $n^{\circ}$ 07.04.176, Maços da população de Santos (1817 a 1846), Arquivo Público de São Paulo.
35. Maestri, M.; O Escravismo no Brasil, Atual Editora: São Paulo, 1994, p. 61-62.

36. Morel, M.; O Período das Regências (1831-1840), Jorge Zahar Editor: Rio de Janeiro, 2003.

37. http://www.histedbr.fae.unicamp.br/doc1_15.htm, acessada em Outubro 2009.

38. Arquivo da Cidade do Rio de Janeiro, códice no 43-1-78, pág. 9 (frente).

39. Arquivo Nacional: Casa Real e Imperial, Mordomia-Mor, cod. 0O, cx 10, pac 2, doc B.

40. Manuscrito do Arquivo do Museu Nacional/RJ: Aviso mandando Alexandre Antonio Vandelli ao Museu Nacional para a separação de plantas e minerais que se possam dispensar para o Colégio de Pedro II. De 14 de janeiro de 1839. Cota ${ }^{\circ}$ BR MN.DR.CO, AO.256.

41. Manuscrito do Arquivo do Museu Nacional: Aviso ordenando o recolhimento ao vice-reitor do Colégio de Pedro II dos produtos naturais emprestados do Museu Nacional. Datado de 15 de março de 1839. Cota $\mathrm{n}^{\circ}$ BR MN MN.DR.CO, AO.258.

42. Filgueiras, C. A. L.; Quim. Nova 2004, 27, 349.

43. Assim como, por exemplo, Francisco Freire Allemão de Cysneiros ministrando a disciplina de Retórica, e Guilherme S. de Capanema ensinando Mineralogia e Geologia.

44. Arquivo Nacional. Livro de Condecorações do Cruzeiro, de Pedro I e da Rosa, códice 14, vol. II, 00141.

45. Juntamente com o botânico Francisco Freire Allemão de Cysneiros.

46. http://www.crl.edu/content/almanak2.htm, acessada em Outubro 2009.

47. Estatutos da Sociedade Nucleo Hortículo Brasiliense, Typographia de Francisco de Paula Brito: Rio de Janeiro, 1849. Podem ser consultados no Setor de Obras Raras da Biblioteca Nacional/RJ sob o n ${ }^{\circ} 70,4,53$.

48. Seu método particular de ensino, aplicado no Imperial Núcleo Hortículo Brasiliense, ficou conhecido à época por "praxedismo". Além dos estatutos mencionados, pode-se verificar a diversidade de assuntos tratados no Núcleo de botânica apenas pelos títulos de algumas suas obras: Brasilismo; Breves Noções para se Estudar com Método a Geografia do Brasil; O Ensino de Praxedes; O Ensino Praxedes para bem Facilitar a Instrução. http://www.literaturabrasileira.ufsc.br/Consulta/Autor. php?autor=14643, acessada em Outubro 2009.

49. O nome da Sociedade, sugerido por Francisco Freire Allemão de Cysneiros, foi uma homenagem a Frei José Mariano da Conceição Vellozo, nascido na Província de Minas Gerais em 1742, e falecido em 1811 no Rio de Janeiro. Foi o autor da importante obra naturalista brasileira "Flora Fluminensis", que expõe o resultado de suas investigações científicas realizadas na Província do Rio de Janeiro durante oito anos. Segundo José Honório Rodrigues em livro publicado pelo Arquivo Nacional em 1961, Flora Fluminensis de Frei José Mariano da Conceição Vellozo - Documentos, cf. páginas 03-09, verificamos que Frei Vellozo terminou o extenso levantamento da flora da região do atual Estado do Rio de Janeiro em 1790. Apenas em 1825, porém, viria a ser publicado parte do seu extenso trabalho.

50. Alexandre Vandelli chegou a exercer a Presidência ad hoc, assinando o diploma de Francisco Freire Allemão de Cysneiros (cf. Biblioteca Nacional/RJ, microfilme MS-548(2), ou diploma ${ }^{\circ}$ I - 28, 05, 062). A primeira diretoria da Sociedade, eleita por unanimidade, foi composta por: Presidente, Francisco Freire Allemão; Secretário Interino, Guilherme Schüch de Capanema; Tesoureiro-Arquivista, Emílio Joaquim da Silva Maia; Paiva, M. P.; Associativismo Científico no Brasil Imperial: A Sociedade Vellosiana do Rio de Janeiro, Thesaurus: Brasília, 2005, p. 28.

51. Estatutos da Sociedade Vellosiana do Rio de Janeiro: manuscritos no Arquivo do Museu Nacional ${ }^{\circ}$ BR MN.DR pasta 3 doc. 157.

52. Bibliotheca Guanabarense - Sociedade Vellosiana de Ciências Naturais do Rio de Janeiro. Microfilme no: PR -SOR 19 (3), Biblioteca Nacional/ RJ, Setor de Obras Raras. 
53. Ref. 50 b, p. 28.

54. Ref. 50 b, p. 28-30.

55. Arquivo Nacional: Documentos da Casa Imperial, Mordomia Mor, entre os anos de 1839 e 1862.

56. Pereira, J. M.; Memoria Sobre a Reforma dos Alambiques ou de Hum Proprio para a Distillação das Aguas Ardentes, Oficina de J. P. Correa da Silva: Lisboa, 1797.

57. Ref. 26.

58. Ref. 26, p. 3, 4 e 16.

59. Filgueiras, C. A. L., Quim. Nova 1993, 16, 155.

60. Vandelli, A. A.; Historia e Memorias da Academia Real das Sciencias de Lisboa, $V, 1818$, p. 427.

61. A preocupação com as quinas vem de muito tempo na economia portuguesa, e o próprio pai legou para Alexandre Vandelli parte desta preocupação. Um exemplo está em uma carta de Thomé Rodrigues Sobral para Domingos Vandelli. Thomé cita frase de Lineu (carta de Lineu, de 12 de fevereiro de 1775, em latim): "Santo Deus, se os portugueses conhecessem as riquezas que a natureza lhes deu, como seriam infelizes tantos outros...". Em Amorim da Costa, A.M.; Primórdios da Ciência Química em Portugal, Biblioteca Breve, Ministério da Educação: Lisboa, 1984, 92, 86.

62. Vandelli, A. A.; Memórias Económicas da Academia Real das Sciencias de Lisboa, 1812. Edição do Banco de Portugal: Lisboa, 1991, 61-65.

63. A gravidade específica é a relação entre a massa da substância e a massa de igual volume de água (aqui, dependeu da fonte da água), a uma temperatura padrão. Esta medida é um legado da Antigüidade, porém é muito prática. Representa-se pelo símbolo $\mathrm{d}_{\mathrm{t}}^{\mathrm{t}}$, onde o expoente é a temperatura da substância e o índice a temperatura padrão da substância de referência. A gravidade específica = densidade da amostra $/$ densidade da água destilada.

64. Vandelli, A. A.; Reflexão sobre a Questão dos Nevoeiros Seccos da Atmosfera do Rio de Janeiro. Apresentada na Sociedade Vellosiana, pelo Snr. Dr. Francisco Freire Allemão. 13 de nov. de 1853. Carta a D. Pedro II, MS, Arquivo do Museu Imperial de Petrópolis, $n^{\circ}$ MS MI M. 126-Doc. 6263.

65. Filgueiras, C. A. L.; Anais do $9^{\circ}$ Seminário Nacional de História da Ciência e da Tecnologia $/ 2^{\circ}$ Congresso Luso-Brasileiro de História da Ciência e da Técnica, Rio de Janeiro, Brasil, 2003.

66. Ref. 50-b, p. 61.
67. Documento do Museu Imperial: MI M.119 - Doc. 5893, $1^{\text {a }}$ parte.

68. Verificamos na Biblioteca Nacional/RJ, pasta C-0108, 018 nº. 003, o manuscrito Requerimento de F.L.C. Burlamaque para Diretor do Museu Nacional, datado de 08/05/1847. Costa carta anexa sob o nº. C-60, 4.

69. Vandelli, A. A.; Apontamentos para a história das minas de Portugal, colligidos pelo ajudante, servindo de intendente geral das minas e metaes do Reino. $1^{\text {a }}$ parte. Academia das Ciências de Lisboa: Lisboa, 1824.

70. Vandelli, A. A.; Zoologia Portuguesa, Biblioteca Nacional/RJ, $n^{\circ}$. 03,1,009-010.

71. Foi um dos muitos alunos brasileiros de seu pai.

72. Vandelli, A. A.; Extracto de 88 Autores para a Nomenclatura Zoológica Portugueza, manuscrito da Biblioteca Nacional/RJ, nº 03,1,009011.

73. Bibliotheca Guanabarense - Sociedade Vellosiana de Ciências Naturais do Rio de Janeiro - Microfilme PR -SOR 19 (3) da Biblioteca Nacional. Estes dois últimos trabalhos não estão localizados até o momento. Provavelmente se perderam, como também menciona: Mello Leitão, C.; A Biologia no Brasil, Companhia Editora Nacional: São Paulo, 1937, 236.

74. Vandelli, A. A.; Retoques e rectificações a alguns elogios insertos na Revista do Instituto Histórico e Geográfico Brazileiro, manuscrito, Biblioteca Nacional/RJ sob o ${ }^{\circ}$. I-48,7,19. Consta na contracapa do original a pequena frase "Coll. Imperatriz Leopoldina". Anexa encontrase carta em frente e verso de Alexandre Antonio Vandelli, datada de 04 de abril de 1859 e em letra praticamente ilegível. Documento encontrado no Gabinete Imperial de S. Cristóvão e levado para a Biblioteca Nacional/RJ.

75. Todos também ex-alunos de Domingos Vandelli, com exceção de Martinho de Mello e Castro.

76. Silva Pontes, R. S.; Revista do Instituto Histórico e Geográfico Brasileiro 1842, 4, 13, 65-80.

77. Vandelli, A. A.; Ingênuos Reparos e Reflexões sobre o Projecto de um Estabelecimento Agrícola, Formulado pelo Gymnasio Brasileiro. Biblioteca Nacional/RJ, Setor de Manuscritos, sob o nº I-32,13,4.

78. Vandelli, A. A.; Refutação da Memória: Onde aprederam e quem foram os artistas que fizeram levantar os templos dos jesuitas em Missões, etc. inserta na revista do IHGB. Impresso, Biblioteca Nacional/RJ, setor de Manuscritos, sob o ${ }^{\circ}$ I-31,25,018. 